\title{
Fit Analysis Using 3D Body Scans and Sports Product Design Methods to Develop a Musical Conductor's Jacket
}

\author{
Susan L. SOKOLOWSKI*1 \\ ${ }^{1}$ Sports Product Design, University of Oregon, 70 NW Couch Street, Portland (OR), USA
}

Key Words: Fit Analysis, Sports Products, Musical Conductor's Jacket

\section{Significance}

Musical conducting is the art of directing a group of individuals in an orchestra, band, symphony or chorus to create music. Since the practice of "modern" conducting was established in the 19th century, conductors have been wearing traditional black suit style or tuxedo jackets. The challenge with this product form is that it has never evolved; it is still made from traditional woven materials and 2D pattern shapes from over 200 years ago. It conflicts with the athletic nature of the conductor's body. It restricts back, shoulder and arm motion, and can be incredibly uncomfortable. Performance and artistry are affected. How could the conductor's jacket be designed and function more like athletic apparel, while respecting the art? This concept paper looked at capturing musical conductor tasks with 3D body scanning and developing a jacket that borrows knowledge from the sports performance apparel industry.

\section{Analysis and Synthesis}

Using Ashdown and Watkins' (1992) movement analysis method for the development and evaluation of a protective coveralls, the fit interface between the musical conductor's body and test jackets was studied using 3D body scanning. Three test jackets (warp, weft, bias) were developed using a reference jacket that the conductor previously performed in. The test jackets were made of medium weight muslin (unlined). Cuts were prepared in a $1 / 2$ step pattern using a 2 -inch grid. By working with the conductor, two body positions were identified to study how the jacket fits at maximum flexion. With IRB approval, 3D scans were captured of the conductor wearing the test jackets, in the defined poses using a Cyberware color scanner (Figure 1).
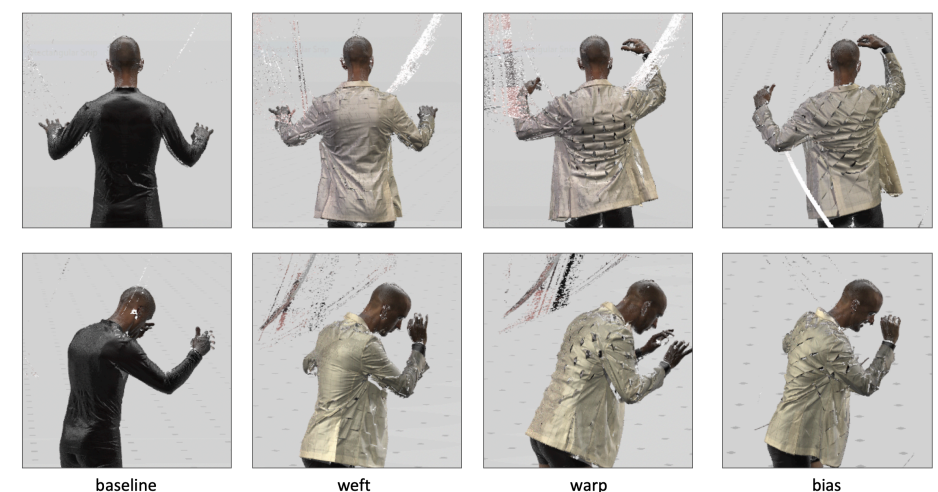

Figure 1. 3D scan outputs of the three test jackets in two positions versus baseline (no jacket).

Page 1 of 2

(c) 2020 The author(s). Published under a Creative Commons Attribution License

(https://creativecommons.org/licenses/by/4.0/), which permits unrestricted use, distribution, and reproduction

in any medium, provided the original work is properly cited.

ITAA Proceedings, \#77 - https://itaaonline.org 


\section{Effects and Findings}

From the 3D scans, it was clear that the armscye region was the focal point of restriction in both the warp and bias conditions. Using sports product design methods of body mapping pattern shapes, performance materials and seams, a formula one race suit-inspired floating sleeve concept was developed with a partial lining. The concept removed traditional armhole seams and replaced them with internal flanges that provided back, shoulder and arm motion. Three materials were used to body map in performance zones: a lightweight stretch twill wool suiting (98\% wool/2\% spandex), lightweight stretch athletic twill (used for board shorts) ( $95 \%$ nylon/5\% spandex), and non-woven interfacing (100\% polyester). Seam types were carefully selected. Where stretch was needed, seams were overlocked. Where seams needed to be stable, they were single needle stitched. Because the jacket was partially lined, the exposed seams were bias taped. The concept was wear tested at several Nutcracker performances in December 2019 (Figure 3).
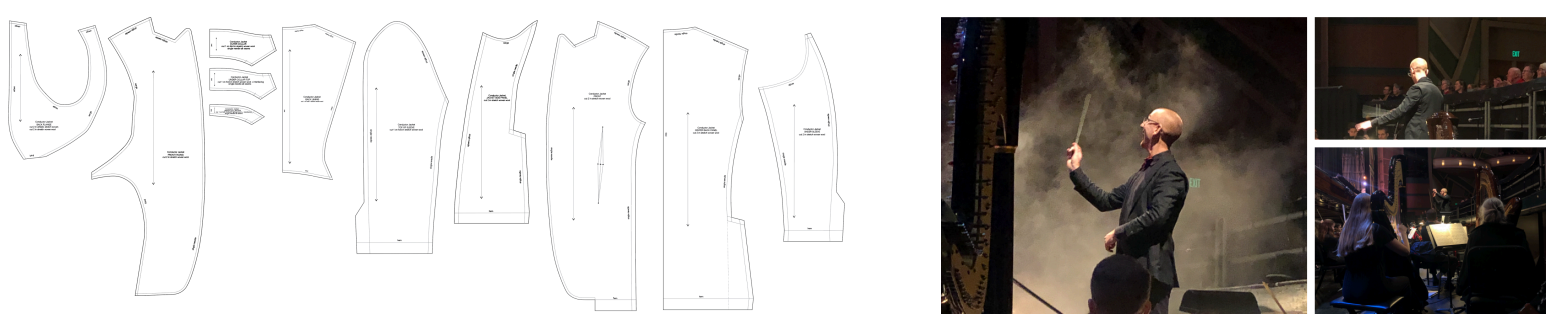

Figures 2 and 3. Jacket concept patterns and wear testing at the Nutcracker ballet performance.

\section{Future Work}

Although the concept was perceived by the musical conductor to perform better than his existing jacket, there are two more exploration paths that the researcher will pursue. The first one includes using the same materials palette but lining the sleeve to add more body (so the sleeve does wrinkle so much). The other path is to increase the overall weight of the stretch wool twill, as the researcher believes the jacket could have a "crisper" aesthetic. There is also future work planned to experiment with new silhouettes, to modernize the aesthetic completely.

\section{Reference}

Ashdown, S. P., \& Watkins, S. M. (1992). Movement analysis as the basis for the development and evaluation of a protective coverall design for asbestos abatement. In Performance of Protective Clothing: Fourth Volume. ASTM International. 